\title{
What Can Be Asked of Interrogators?
}

\author{
MICHAEL SKERKER
}

\begin{abstract}
This chapter considers how the rights and interests of interrogators should shape interrogation ethics. What can States ask of their police and military interrogators, given that certain interrogation techniques may have lasting moral and psychological effects on practitioners? I reject a prominent theory advocating a complete separation between professional and nonprofessional moral spheres as well as a theory that expects professionals to martyr themselves by using expedient methods even if they are conventionally considered immoral. I develop a theory of professional ethics involving a triangulation among the rights and interests of professionals, their clients, and their "targets." The chapter applies the preferred standard of professional ethics to different modern interrogation methods. It draws on interviews with over a dozen interrogators to highlight concerns about the emotional toll that certain techniques may have on the interrogator. I conclude with recommendations on how interrogators using modern rapport-based techniques can engage in selfcare to avoid compassion fatigue and moral injury.
\end{abstract}

\section{INTRODUCTION}

The purpose of this chapter is to consider what a state's citizens can ask of state agents such as police, military, or intelligence interrogators. Discussions of interrogation ethics often focus on the rights of suspects, ${ }^{1}$ but it is important to also consider the rights and interests of interrogators, given the unique risks and stresses

1. As I do in An Ethics of Interrogation (University of Chicago Press 2010) and 'Ethical Perspectives on Interrogation: An Analysis of Contemporary Techniques' with Maria Hartwig and Timothy Luke in Jonathon Jacobs and Jonathan Jackson (eds), The Routledge Handbook of Criminal Justice Ethics (Routledge 2017) 326.

Interrogation and Torture: Integrating Efficacy with Law and Morality. Steven J. Barela, et al. (C) Oxford University Press 2020. Published 2020 by Oxford University Press. 
of their jobs. After developing a model of professional ethics apt to address this topic, I will consider the effects on the interrogator of some new non-accusatory interrogation techniques. There will be an extended discussion of operations where an undercover interrogator engages a suspect or intelligence target in detention without identifying himself as a state agent. These "false flag" operations-known as "Perkins" operations in American law enforcement circles-are an interesting test case for my model of professional ethics, because while they are far less harmful and harrowing to the suspect than coercive or accusatory methods, they may be more harmful to the interrogator.

c9.P3 Section II of what follows considers two approaches to professional ethics that suggest that state agents can be asked to do whatever efficiently meets their professional goals. After discussing the flaws of these approaches, Section III introduces a model limiting professional behavior to actions that citizens could consent to being either the agent or recipient of such methods. Section IV discusses different kinds of interrogation methods, their effectiveness, and potential risks to interrogators employing them. Section V discusses concerns regarding Perkins interrogations in particular. Sections VI and VII consider proposals for how interrogators might interact with suspects in such a way as to avoid moral injury.

This chapter's method is different than some of the others in this volume. I am an ethicist, rather than a psychologist. The latter half of the chapter draws on a series of interviews and conversations conducted with police and military interrogators as well as my near decade-long involvement with the advisory committee for the U.S. government's High-Value Detainee Interrogation Group Research Unit, an interagency task force that funds research into lawful interrogation methods and trains federal and state law enforcement agencies in their use. I will be raising concerns with particular interrogation techniques articulated to me by some interrogators, but not making assertions based on clinical data. Hopefully, the questions I raise will stimulate empirical researchers to pursue research programs to determine if the relevant anecdotes are illustrative of broader trends.

\section{RESPONSIBILITY TO STATE AGENTS: TWO EXCLUSIVIST ACCOUNTS}

What responsibility do citizens have to state agents who engage in unsavory actions on those citizens' behalf? As a society, we should be concerned about setting up state agents for moral and emotional struggles if we train them in professional techniques that damage them morally or psychologically. The training of service personnel to use deadly force is an instructive case. Startled by the low firing rates of World War II soldiers and Marines, the U.S. military endeavored to scientifically overcome service members' natural reluctance to kill. Through operant conditioning, service personnel were (and are) trained to reflexively shoot in response to certain prompts in highly realistic training scenarios. U.S. service personnel now lethally fire with markedly improved efficiency, ${ }^{2}$ but the military has invested little research or time to training service personnel how to be "capable of handling the 
moral and social burdens of these acts." 3 There is a potentially exploitational relationship between the state and service personnel when the state trains the bodies of service personnel to unthinkingly perform the actions the state needs without concern for the emotional or moral impact of these actions.

The literature on professional ethics offers different answers to the question of what a state can ask of its agents. There are two significant approaches in the literature arguing that the norms guiding professionals are independent of broader moral principles. In what follows, I will reject these approaches: one that requires state agents to morally sacrifice themselves on behalf of the state and another that unconvincingly argues that any professionally expedient action is morally upright and so should not cause the professional undue stress. In their place, I will propose a model that presents properly-constructed professional norms as institutionally mediated expressions of the moral responsibilities that all people share.

\section{A. The Moral Anguish Approach}

An approach Leslie Griffin calls the "moral anguish" approach accepts the universality of a single morality without any carveouts for professionals but asserts that morality is incomplete, inadequately adapted to real-world contexts. This inadequacy forces some professionals to improvise and depart from putatively universal moral rules in order to bring about morally good outcomes. ${ }^{4}$

The moral anguish approach sees the professional as judged by a broader morality while doing what seems necessary to bring about the good ends of his profession. While usually invoked to justify political violence or deception, the moral anguish approach will appeal to the many readers who have occasionally bent or ignored rules in order to bring about a good effect. One might acknowledge that state laws or the procedures of one's profession or organization are designed to bring about good effects in most cases but also acknowledge that legislators cannot think of every eventuality. One might therefore assert that rule-bending improvisation is sometimes appropriate by conscientious people in order to meet the spirit of the law. ${ }^{5}$

Dennis Thompson makes the elegant point that while laypeople might refrain from committing expedient immoral acts aimed at a morally worthy result with the quasi-metaphysical thought that "things will work themselves out," the institutional

\section{3. ibid 295.}

4. Discussed in Leslie Griffin, 'The Problem of Dirty Hands' (1989) 17 (1) Journal of Religious Ethics 31, 38; Max Weber, 'Politics as a Vocation' in HH Gert and C Wright Mills (eds), From Max Weber: Essays in Sociology (Routledge 1977) 77, 120; Michael Walzer, 'Political Action: The Problem of Dirty Hands' (1973) 2(2) Philosophy and Public Affairs 160; CA Coady, 'Messy Morality and the Art of the Possible' (1990) 64 Proceedings of the Aristotelian Society 259, 260-62; Dennis Thompson, 'Moral Responsibility of Public Officials: The Problem of Many Hands' (1980) 74 American Political Science Review 905, 906; Stephen De Wijze and Tom Goodwin, 'Bellamy on Dirty Hands and Lesser Evils: A Response' (2009) 11 British Journal of Politics and International Relations 529, 537.

5. Peter Digeser, 'Dirty Hands and Imperfect Procedures' (1998) 26(5) Political Theory 700, 709 . 
structure of certain professions makes certain professionals feel that they must act within a given time frame. It is the short window of time for action that produces the wretched list of expedient options. ${ }^{6}$ Consider, how many justifications of torture rely on there being a ticking bomb?

69.P10 Professionals facing threats to public safety have to martyr themselves, the argument goes, doing the dirty work necessary to achieve good ends in a fallen world; they have to use the broken tools they inherited, and choose among options narrowed by other people's stupidity and viciousness. ${ }^{7}$ Working himself up to a rare froth, Max Weber writes, "[The politician] must know that he is responsible for what may become of himself under the impact of these paradoxes. I repeat, he lets himself in for the diabolic forces lurking in all violence."

Those advocating the moral anguish approach to questions of professional morality seem to treat morality as a social artifact, like a body of law, which has been developed over time through a combination of social practice, reflection, critique, and justification. Moral rules only pertain to situations that frequently face ordinary people since on this conception, morality is constructed through historical consensus. ${ }^{9}$

Cases urging the moral anguish understanding of professional morality can arise in two ways. First, the professional feels trapped between opposing prescriptions of professional morality and nonprofessional morality: the soldier who feels it is his duty to kill enemy troops but still feels that he has done wrong in killing someone in an ambush. Second, the professional feels trapped between opposing prescriptions of professional norms and an expedient plan of action violating those norms: the political official who feels that parliamentarians have to be deceived in order to carry out some covert action vital to national security.

What is occurring in fraught professional situations suggesting the anguish approach is that the professional is able to step outside the ingrained way of looking at things and perceives that the moral rules have a certain purpose, best served by actually violating a moral rule. Yet rule compliance in general also has a purpose in creating social order-there would be chaos if people routinely picked and chose for themselves which moral rules to ignore. So the conscientious rule breaker must submit to punishment in order to uphold the goodness of the normative order. By submitting to punishment, he signals to others that they ought not to imitate his rule breaking. He is thus a perfect sacrifice, punished in the court of his conscience and in the external world as well.

So, on this view, an interrogator may need to deceive or emotionally manipulate a suspect, but then he should probably feel bad about taking advantage of the suspect's trust. It would be important for the interrogator to feel ashamed of his 
professional behavior lest he become cavalier about doing similar things in his personal life.

In this chapter, I will develop an approach to professional ethics limiting professional norms to what would be consent worthy to all affected by them. Such an approach would preclude any set of professional norms and tactics that morally or psychologically harm police officers. Before turning to this account, we can see that any kind of egalitarian morality of the sort undergirding liberal democracies would have to reject a social structure in which the vital outputs of professions are secured through the moral devastation of those in the profession (egalitarian morality directs us to afford all people equal levels of moral respect)..$^{10}$ Laypeople cannot ask their agents to do things they themselves would and should refuse to do because of the risk to their moral and psychological health. To be clear, it does not matter that a philosopher might be able to explain to an anguished professional why what he did was truly the best thing. As far as the professional and other nonphilosophers understand, he has done something evil; he actually feels corrupted and suffers the attendant damage to his character. ${ }^{11}$ This argument would hold until the philosopher's justification of apparently immoral professional acts became so widely accepted that the conscientious professional would be free of both public condemnation and his own pangs of conscience.

\section{B. The Separatist Account}

Another approach, which I will call the separatist approach, indicates that laypeople can ask interrogators to engage in whatever tactics efficiently garner confessions. ${ }^{12}$ There is nothing to worry about relative to their moral injury because professional ethics is a separate sphere from ordinary morality.

This approach holds that the professional zealously pursuing the characteristic ends of his profession is acting rightly, even if he is doing things that are immoral according to the lights of nonprofessionals. Niccolo Machiavelli forever associated his name with this approach, writing, "it is necessary to a prince, if he wants to to do things that would corrupt their characters. Wolgast, Ethics of an Artificial Person (Stanford University Press 1992) 104; Mendus, Politics and Morality (Polity 2009) 112. convictions to reject consequentialists' attempt to dissolve dirty hands paradoxes. Thompson, Political Ethics... (n 6) 16-17.

12. Luther and somewhat more arguably, Machiavelli, are classic exponents of this separation for state agents. Calvin advocates it for all professionals, Martin Luther, 'Whether Soldiers Too Can be Saved?' Nicolo Machiavelli, The Prince; John Calvin, Sermons of M John Calvin upon the Epistle of Saint Paul to the Galatians [Lucas Harison and George Bishop 1574] 307. Twentiethcentury exponents of this view include Carr, Friedman, Freedman, and Churchill; Albert Carr, 'Is Business Bluffing Ethical?' (1968) Harvard Business Review <https://hbr.org/1968/01/ is-business-bluffing-ethical>; Milton Friedman, 'The Social Responsibility of Business is to Increase its Profits' in Thomas Donaldson and Patricia Werhane (eds), Ethical Issues in Business (6th ed, Prentice-Hall 1999) 154; Larry Churchill, 'Reviving a Distinctive Medical Ethic' (1989) 19(3) The Hastings Center Report 28; Benjamin Freedman, 'A Meta-Ethics for Professional Morality' (1978) 89(1) Ethics 1. 
maintain himself, to learn to be able not to be good. ... for if one considers everything well, one will find something appears to be virtue, which if pursued would be one's ruin, and something else appears to be vice, which if pursued results in one's security and well-being." ${ }^{\prime 3}$

69.P18 Moral compartmentalization between professional and personal personas is wholly appropriate on this view. The economist Milton Friedman writes,

c9.P19 In his capacity as a corporate executive, the manager is the agent of the individuals who own the corporation or establish the eleemosynary institution, and his primary responsibility is to them.... Of course, the corporate executive is also a person in his own right. As a person, he may have many other responsibilities that he recognizes or assumes voluntarily-to his family, his conscience, his feelings of charity, his church, his clubs, his city, his country. He may feel impelled by these responsibilities to devote part of his income to causes he regards as worthy, to refuse to work for particular corporations, even to leave his job, for example, to join his country's armed forces.... But in these respects he is acting as a principal, not an agent; he is spending his own money or time or energy, not the money of his employers or the time or energy he has contracted to devote to their purposes. ${ }^{14}$

C9.P20 Professional morality is usually consequentialist (goal oriented) in its overall orientation on the separatist view, as it is indexed to the delivery of the profession's characteristic ends. The normative sense of professionals is privileged over that of nonprofessionals because professionals know best how to efficiently deliver the profession's characteristic ends. It follows that professionals have no reason to feel guilty over their proper professional behavior because their professional behavior is not answerable to nonprofessional (i.e., "ordinary") morality. They can only be criticized, and perhaps feel guilty, over failing to properly execute their professional imperatives. So interrogators are acting appropriately if they maximize the number of truthful confessions or the amount of accurate intelligence they garner. The separatist approach does not indicate a clear prescription for how to allay interrogators' emotional exhaustion, guilt, or moral qualms over manipulating or deceiving suspects, other than maybe screening for less-sensitive interrogators and continually assuring them that there is no reason to feel uncomfortable.

The separatist advocate has a hard task in showing that society really is benefited more than an alternative arrangement when all professionals zealously pursue the characteristic ends of their professions without regard to any other moral constraints. It is easy to imagine the social harm that can be done if business people and bankers seek to make as much money as possible; if police prevent and detect crimes by any expedient method; if service members seek to win their engagements using any weapon whatsoever, and so on. That said, pointing to environmental degradation, human rights abuses, and war crimes cannot settle the argument against this separatist advocate, because perhaps a sufficiently broad perspective would 
redeem the separatist approach as really causing more net good than an alternative arrangement forcing professionals to observe some moral side constraints.

Readers familiar with the standard critique of cultural relativism should be dubious of the separatist's claim that there are distinct moral spheres appropriate to the different professions separate from nonprofessional morality. The standard critique of cultural relativism states that the proponent of the notion that "there are no universal moral truths" contradicts himself by assuming there is at least one universal truth: namely, that there are no universal truths. Similarly, the separatist explicitly denies that there is a single, comprehensive moral system binding on all people. Yet barring some comprehensive ordering of goods, rights, and duties, how does the separatist know that there really are distinct moral spheres-and that the police officer, for example, neglects no duties by only adhering to police norms when he is on the job?

One of the first Western thinkers to assert that it was proper for all professionals to simply focus on their professional imperatives while at work was the theologian Jean Calvin. On his view, God called people to different professions and providentially balanced the independent behavior of the professions, like a conductor integrating the different instruments of an orchestra. There is not a thorough separation of professional spheres, viewed from the divine perspective. The soldiers, lawyers, and doctors are all playing the same score. By contrast, the modern, secular separatist proponent assumes that he himself has this universal normative perspective legitimating the complete separation of professions while at the same time implicitly denying a comprehensive morality applicable to professionals. He asserts that there is, and is not, a score for all to follow. The secular versions of the separatist thesis thus seem to lack the conceptual resources to make the thesis coherent.

Another similarity between relativism and the separatist thesis is the dismissiveness of both positions toward inter-doctrinal critiques, that is, criticisms that come from outsiders who do not understand what things are like for insiders. See the earlier discussion of Friedman's impatience with critiques of business executives' seemingly immoral or amoral decisions. One could make consequentialist arguments to the effect that the good done by professionals zealously pursuing their professional imperatives outweighs the harm. One could also make a fair play argument that those enjoying the services provided by professionals cannot condemn the practices making those services possible. Yet separatists like Friedman typically do not make these arguments, relying on stipulation instead. And it simply seems inadequate to say that a plant manager who maximizes revenues one quarter by releasing effluent into local rivers has no responsibility to the people who rely on those rivers for drinking water. Barring a robust argument, we ought not to defer to professionals' role responsibilities if these roles or the profession violate people's rights or cause serious harm. ${ }^{15}$ Generally speaking, special obligations based on contract, relation, or friendship do not permit one to violate others' rights.

Finally, the moral compartmentalization apparently necessary for the professional occupying two distinct moral systems would seem on its face to promise 
adverse psychological and moral effects. ${ }^{16}$ How can one reconcile performing actions condoned in one moral system and condemned in another when one adheres to both moral systems? Intuitions about the negative effects of compartmentalization are supported by the myriad memoirs published by service personnel in the last two decades describing their anguish over actions departing from the normal bounds of morality and Jonathan Shay's work showing severe post-traumatic stress disorder (PTSD) and moral injury among service personnel who committed serious moral infractions. ${ }^{17}$

c9.P26 Police ought not to be taught to simply do whatever works in interrogation and to assume that those actions are morally right. We should not assume that superficially unsavory or emotionally trying, but efficacious, interrogation tactics are morally sound, nor that interrogators can and should then emotionally adapt to their performance.

\section{RESPONSIBILITY TO STATE AGENTS: THE COLLECTIVE MORAL RESPONSIBILITY APPROACH}

I will now sketch out an approach to professional ethics I think is more promising than those already discussed. This approach will help guide our thinking about what we can ask of state agents like police officers. Space limitations will require a fairly terse statement of my position, the initial part of which is based on work by Seumas Miller. ${ }^{18}$

By virtue of natural properties, human beings have positive and negative claim rights, imposing reciprocal positive and negative duties on all others. We can speak of any group of people as having an aggregation of individual rights in the sense that one encountering a group of five people has a duty to respect the rights of five people. Individuals also have joint moral rights insofar as they are members of certain groups. These are rights that attach to individuals but only as group members, for example, a right of national determination or a right to secede. A joint moral right of special relevance to this chapter is the right to security: a right to live in an environment that is free of rights violations to a degree that people are not unduly inhibited from pursuing different personal and joint projects. People, of course, have basic needs for the material necessities of life as well.

The aggregation of individual rights, joint moral rights, and aggregated human needs create collective moral responsibilities to protect and address those rights and fulfill those needs. Collective moral responsibilities are moral responsibilities of groups to attend to these rights and needs because only groups can effectively

16. Justin Oakley and Dean Cocking, Virtue Ethics and Professional Roles (Cambridge University Press 2006) 144; Andreas Eshete, 'Does a Lawyer's Character Matter?' in Joan Callahan (ed), Ethical Issues in Professional Life (OUP 1988) 392, 395.

17. Jonathan Shay, Achilles in Vietnam (Scribner 1994); Tony LaGouranis, Fear Up Harsh (Caliber 2007); Bill Edmonds, God is Not Here (Pegasus 2015); Joshua Phillips, None of us Were Like this Before (Penguin 2012).

18. A fuller version is in Chapter 6 of my The Moral Status of Combatants (under contract, Routledge 2019). See Seumas Miller, The Moral Foundations of Social Institutions (Cambridge University Press 2010) 57-80. 
meet them. Collective responsibilities attach to individuals but only if they are members of certain types of groups.

Typically, these collective moral responsibilities are acquitted by creating and supporting institutions to address the relevant rights, such as schools, hospitals, businesses, churches, and militaries. ${ }^{19}$ These institutions are essentially outcome oriented, set up to foster, create, and protect the collective moral goods (e.g., health, education, security) that protect rights and fulfill morally important needs. ${ }^{20}$

The collective moral responsibility of society is largely, though not completely, transferred to the professionals who work in morally vital institutions. These institutions are created to acquit collective moral responsibilities, so professionals have a joint moral duty to comply with their properly-constituted professional imperatives (a joint moral duty is a moral duty to do something that can only be done in a group). ${ }^{21}$ Thus, professional imperatives are not simply like the obligations of a member of a club, instrumental to the club's end, but moral duties, with the weight to compete with other moral duties. They are moral duties since they meet others' positive rights, protect negative rights, and produce the goods to meet morally important needs.

There are not two moralities. Morality encompasses some duties applying to most people and some duties that only apply to members of certain communities. The latter might include duties applying to members of affluent States vis-à-vis members of poorer States (but not vice versa), duties of former colonial powers vis-à-vis members of their ex-colonies, and duties that apply to members of certain institutions. There are both individual moral responsibilities and collective moral responsibilities, the latter that can best be met by participating in institutions or by supporting their work.

c9.Р33 Properly constituted professional norms have moral power because they are what guide the professional's actions to the institutions' morally vital ends. Professional norms tend to be chiefly ends oriented, directing the professional to educate children, heal the sick, protect the innocent, and so on, but they are also constrained by deontological concerns reflecting rules that should win the approval of all affected by the professionals' actions (here I diverge from Miller). Deontological rules are those that are binding in all circumstances, regardless of consequences. These constraints specify how the institutional imperatives are to be met, guided by stakeholders' presumed aversion to being grossly wronged in some areas while being assisted in others. The orientation toward collective goods and deontological concerns about the means of attaining them are the ingredients of professional norms, and so, the content of professional duty.

c9.P34 Broadly speaking, the facilitation of moral goods explains why professionals are morally permitted or obliged to sometimes act differently from laypeople in similar situations. Unlike norms pertaining to laypeople, these norms are meant to facilitate collective moral goods through institutional mechanisms, delivering to a wide number of people impartially, consistently, over time regardless of the 
particular composition of the institution's staff. This institutional frame can even direct professionals to act in an opposite manner of a layperson confronting a similar situation. For example, a police officer might tell a suspect that he does not have to volunteer incriminating information when the suspect spontaneously begins to explain why he killed someone or a soldier may shoot a sleeping enemy soldier he believes will threaten him in the future. Professionals should behave in this way even though laypeople usually should encourage a wrongdoer to confess criminal information and even though laypeople may not engage in preemptive violence. The divergence of action-guiding norms for laypeople and professionals who both have individual duties to act justly and collective moral responsibilities to facilitate justice and security stems from the following differences in their aims and capabilities. Professionals are seeking mainly to protect joint moral rights and aggregated goods, which the layperson usually cannot protect directly. Further, professionals usually do not directly protect individual rights, but do so in an institutional context that indirectly secures the rights of many. For his part, the layperson does not have access to institutional mechanisms and so can only protect those rights in an ad hoc, short-term manner.

A professional duty to meet the collective moral right of security is too vague to be action guiding for police. Many security-seeking tactics could be unacceptable to the community supposedly benefited by them for reasons ranging from brutality to ineffectiveness. We can take advantage of the criterion of universalizability inherent in most schemes of rights and duties to further delineate relevant professional duties. We can consider if everyone affected by a potential tactic or norm would endorse it, including the three relevant stakeholding groups for police actions: police officers themselves; suspects; and the rest of the public, including crime victims. ${ }^{22}$ In the abstract, we can see that these groups would endorse tactics and norms that strike an optimal balance between being practically efficacious and rights respecting. Among those tactics and norms that are the most practically effective (reliable, efficacious, proportionate, and efficient) among available alternatives, we can imagine rational consent extending to those tactics that best respect the rights of all affected parties. This rights-respecting element will itself be the product of an optimal balancing of the interests of the three stakeholder groups. On this point, it is important to bear in mind that the beneficiaries of security-seeking norms and tactics could also be the targets of the relevant norm-guided actions in the event that they are suspected of crime or they could be bound by these norms if they are state agents. The hypothetical consent approach is preferable to alternatives worked out by the theorist in advance because contingent local factors can indicate different morally preferable tactics. It might well be rational to consent to more invasive security procedures in high crime areas or cruder investigative techniques if the government cannot afford more advanced technologies.

This model gives us a framework for answering the question of what can be asked of state agents. In short, no citizen can ask his state agents to do things he would 
not be willing to do himself, provided adequate training. We can then rule out a series of actions that would violate a person's rights, since there is no basis to model people in the abstract rejecting consistent violation of their basic rights. A generic person cannot be modeled in the abstract as endorsing rules stripping him of rights to marry; to worship freely; to vote as he wishes; believe what he wants; and so on, so we can rule out instructions for state agents forbidding marriage (as was the case in the 19th century for British military personnel), prohibiting or mandating a particular religious affiliation, party affiliation, and set of beliefs, etc. One cannot in the abstract be modeled as endorsing actions prejudicial to life, bodily integrity, and health, so state agents cannot be ordered on suicide missions; cannot be ordered to have sexual relations with a target; and cannot be ordered to ingest narcotics as part of an undercover operation. For the same reason, they cannot be ordered to engage in actions destructive to their long-term mental, moral, or emotional health.

c9.P37 More work needs to be done to specify the limits of what can be asked of state agents, given attention to mental, moral, and emotional health. Yet we ought not to expect too specific a set of prescriptions given the normal variability in human psychology and the lack of consensus on what exactly is constituted by mental, moral, or emotional health. We would want to avoid actions leading to flagrant indicators of harm, like higher than average rates of suicide, substance abuse, divorce, depression, domestic abuse, or any occurrence of PTSD or moral injury. Again, without delving too deeply into moral psychology, we can imagine a generic person (imagining himself as a police recruit, for instance) rejecting professional norms and tactics that negatively affect him to the point of being unable to have a healthy family, romantic, civic, or social life. Relatedly, we can also imagine a rejection of professional norms and tactics that inhibit an officer's neighbors, friends, and family members from having similarly healthy lives.

Finally, if we identify norms and tactics that are consent worthy to the three stakeholder groups, we still have to train professionals in such a way that they can internalize the norms and understand how to properly implement the tactics. For example, it has been shown that PTSD tends to accrue with greater frequency and intensity to people who have committed serious moral infractions. So a disservice would be done to police officers if they were instructed to respect suspects' rights with a wink that suggested that no one will question them about what occurs in the interrogation booth or if they were given inadequate training in interrogation approaches so that they effectively did not know how to interrogate someone in a rights-respecting manner. Training might even extend to discussing the appropriate attitude to cultivate toward suspects when employing the approved tactics. Thinking about one's professional tasks in a particular way might contribute to, or detract from, mental, moral, and emotional health. We will now turn to that subject.

I will now apply the model of professional ethics just articulated to novel interrogation methods. This section will describe different interrogation styles with an emphasis on the effects of these styles on interrogators. 


\section{A. Different Interrogation Styles}

- As their name suggests, confession-based models attempt to elicit a confession from suspects (I will also refer to these models as accusatory models). These models have three basic elements: custody and isolation, which increases stress and the motivation to escape the situation; confrontation, during which the interrogator accuses the suspect of the crime and stresses the futility of denial; and maximization/minimization, during which the interrogator states the penalties associated with continued denial, and the benefits associated with offering a confession. ${ }^{23}$ The interrogator takes the suspect on a fairly harrowing emotional journey in which he attempts to create psychological pressure that can only be relieved through confession, or so the interrogator suggests. The interrogator may also implicitly minimize the cost of confession by suggesting that the crime or the penalties are not very severe. With less emotional suspects, the interrogator may suggest that it is the suspect's rational self-interest to confess.

- Information-gathering approaches draw on research geared toward helping crime witnesses and victims remember details of crimes. These approaches seek to gain an understanding of the incident in question rather than a confession. ${ }^{24}$ The interrogator explains the purpose of the inquiry, the process of the interrogation and investigation, and the scope of the suspect's rights. He then invites the suspect to narrate his account of the incident in question, pressing him to clarify details and contradictions. The interrogator does not engage in deceptive or emotionally manipulative gambits.

- As with information-gathering approaches, strategic interviewing seeks reliable information rather than a confession, but operates on the assumption that innocent and guilty suspects have different counterinterrogation strategies than material witnesses. Taking advantage of the fact that lying is mentally taxing, one technique under the heading of strategic interviewing attempts to increase the cognitive load of suspects by asking them to do things like draw a picture of a place they claimed to have visited or narrate remembered events in reverse order. Not only are liars unable to do these things, the added mental effort required to cope with the new requests leads to demonstrable signs of deception. The strategic use of evidence technique (SUE) has the interrogator invite the suspect to narrate his version of events without revealing that the interrogator already has inculpating evidence. The interrogator's revelation of the information typically prompts different types of

23. Saul Kassin, Steven Drizin, Thomas Grisso, Gisli Gudjonsson, Richard Leo, and Allison Redlich, 'Police-Induced Confessions: Risk factors and recommendations' (2010) 34 Law and Human Behavior 3.

24. For discussion of the transition away from confession-based interrogation models in the United Kingdom, Norway, and other countries see Chapter 6 of this volume by R Bull and A Rachlew. 
reactions from liars and truth tellers, helping the interrogator to confirm or disconfirm his suspicions.

- The Scharff technique takes into account that suspects will be trying to ascertain what the interrogator already knows and what he wishes to know; the suspect will admit the former and will attempt to conceal the latter. The interrogator accordingly tries to conceal what he does not know and give the suspect the impression that he already "knows all." Amid a fairly comprehensive account of the event in question, the interrogator will intentionally misstate certain details, which the suspect will typically hasten to correct without realizing that he just furnished what the interrogator wanted to know.

With all the strategic interviewing techniques, the interrogatee is treated to an extent as a partner in a truth-seeking endeavor rather than an adversary whose psychological defenses must be overcome. Even though the interrogator engages in strategic behavior in order to expose deception and prompt the revelation of information, the interrogator does not engage in threatening, demeaning, psychologically coercive, or minimizing behaviors (making a crime seem less grave than it is). A contrast with the confession-based models is a consistent emphasis on developing rapport with the suspect (confession-based models may involve rapport). What is rapport? Interrogators often recognize the importance of developing rapport in order to overcome resistance ${ }^{25}$ even if there is disagreement about what constitutes it. ${ }^{26}$ Scholars have recently devoted a good deal of work to sharpening the definition of rapport and identifying the precise relationship between a given construal of rapport and cooperation in interrogation. ${ }^{27} \mathrm{~A}$ theoretical conception referenced by many scholars has the following elements. Parties who have reached rapport are focused on the same goal; they have positive attitudes toward one another; and their conversation flows freely with nonverbal behavior (head nods, smiles, eye contact) aligned..$^{28}$ Rapport can be developed by demonstrating respect and empathy toward a suspect, empowering him to tell his own story, and listening carefully without judgment or condescension. The development of rapport also seems to be aided by the interrogator's identification of commonalities with the suspect through the selfdisclosure of personal information. ${ }^{29}$

25. Melissa Russano, Fadia Narchet, Steven Kleinman, and Chris Meissner, 'Structured Interviews of Experienced HUMINT interrogators,' (2014) 28 Applied Cognitive Psychology 847.

26. ibid.

27. See Chapter 5 of this volume by L Brimbal, Col SM Kleinman, S Oleszkiewicz, and CA Meissner.

28. Linda Tickle-Degnen and Robert Rosenthal, 'The Nature of Rapport and its Nonverbal Correlates' (1990) 1 Psychological Inquiry 285. 
A specialized technique under the heading of strategic interviews that pursues this avenue of identifying commonalities is the Perkins interrogation. A similar operation in military or intelligence contexts is known as a false flag operation. In a Perkins interrogation, an undercover officer posing as a fellow arrestee "meets" a suspect in pre-arraignment holding - after the suspect has been arrested, but before he has been formally charged and read his Miranda rights. The undercover officer presents himself as someone in the same boat as the suspect, likely from the same neighborhood and background, facing the same anxieties now that he is facing arraignment. After establishing a bond, the conversation between the two naturally turns to the reason for their arrest and then, whether or not the suspect is guilty.

As currently practiced by at least one major American urban police department (which I will call "Department 1"), Perkins interrogators engage in scientifically validated rapport-building techniques as well as the strategic use of evidence. ${ }^{30} \mathrm{With}$ respect to the latter, detectives may stimulate the conversation between the suspect and the undercover officer by "drip-feeding” evidence. For example, a detective may walk past the cell and say, "Smith, we'll take your statement just after we finish reviewing the security videotapes from the scene."

The U.S. Supreme Court reasoned in Miranda v. Arizona that suspects had their privilege against compelled self-incrimination violated when the "inherent pressure" of the interrogation room made them feel as though as if they had to confess. The Court concluded in Perkins v. Illinois, the 1986 case from which the interrogation style takes its name, that official pressure from the state does not exist in a situation where the suspect does not realize that he is talking to a police officer.

\section{B. Evaluating Interrogation Methods}

69.P48 We might think of interrogation techniques as arranged on a spectrum from the most harsh, and, as it happens, least effective techniques, at one end of the spectrum, to the least harsh and most effective at the other end. I did not mention torture in the preceding section as it is not, strictly speaking, an interrogation method. The deliberate infliction of gratuitous physical and mental suffering can be employed for multiple purposes. Obviously, the most harsh way of attempting to elicit information from a suspect, interrogatory torture is also notoriously unreliable at producing accurate information.

30. The anecdotes regarding the Perkins operations come from eight interviews and conference calls conducted 2016-2018 with detectives from the Major Crimes division of Department 1 , as well as detectives from other nearby municipalities. Their interrogation and undercover techniques are not classified, but are considered "close hold" — not to be broadly disseminated. Detectives communicated with me with the understanding that the identity of undercover officers and the departments involved would be kept confidential. I will refer to detectives and departments in numerical code. Department 1's actions are significant as the department receives training from the High-Value Detainee Interrogation Group, the U.S. Federal Task Force that funds some of the research into non-accusatory techniques discussed in this volume. Also, Department 1 is known as a trendsetter in American law enforcement circles and trains detectives and agents from many other municipal and even federal agencies. 
The conventional wisdom among many American detectives throughout the latter half of the 20th century and likely to the present day ${ }^{31}$ is that confession-based approaches have a high degree of efficacy. Yet research has indicated that they also pose a demonstrable risk of generating false confessions. ${ }^{32}$ Significantly more humane than physical coercion, confession-based interrogations are still deceptive, sometimes emotionally manipulative, sometimes involving lying, and often unpleasant for suspects to endure.

c9.P50 Research indicates that information-gathering and strategic interviewing approaches are highly reliable; ${ }^{33}$ more apt to accurately distinguish liars from truth tellers; ${ }^{34}$ produce fuller narratives (e.g., producing more corroborating details) than confession-based models; ${ }^{35}$ and run a lower risk of producing false confessions. ${ }^{36}$ The new techniques are typically more respectful of the suspect's autonomy and create a less harrowing environment in the interrogation room compared to confession-based models. Non-accusatory approaches largely preclude threatening suspects; presenting them with false evidence; demeaning them; exposing them to significant psychological pressure; or otherwise subjecting them to tactics that could be expected to produce false confessions.

The information-gathering approach lacks deceptive elements, assuming that suspects are informed that they are criminal suspects or suspected security risks. The Scharff and SUE interrogator do not extend the same respect for a suspect's autonomy as information-gathering approaches in that they rely on an asymmetry

31. I have frequently heard about resistance to abandoning confession-based techniques from those who attempt to train experienced interrogators in new scientifically validated techniques. A typical response is this: "Why should I give up something that has always worked for me?" Meeting with Assistant District Attorney 1 and Detectives \#5 and 6, Department 2 (a moderatesize county) (11 April 2017); High-Value Detainee Interrogation Group committee meeting (13 June 2017, Washington DC); High-Value Detainee Interrogation Group committee meeting with 10 Army interrogators, (19 January 2016, Vienna VA); meeting with Detectives \#7, 8, and 9 in Department 3 (a large urban department) Intelligence Unit (13 July 2018).

33.ibid; confession rates did not drop after the United Kindom abandoned confessionbased models in favor of information-gathering approaches in the mid-1980s; B Irving and I K McKenzie, Police Interrogation: The Effects of The Police and Criminal Evidence Act (Police Foundation of Britain 1989); P Softley, Police Interrogation: An Observational Study in Four Police Stations, Home Office research Study no. 61 (HMSO 1980). See Section II in this volume for further citations.

34. Maria Hartwig, Per Anders Granhag, LA Strömwall, and O Kronkvist, 'Strategic Use of Evidence during Police Interrogations' (2006) 30 Law and Human Behavior 603; Timothy Luke et al, 'Training in the Strategic Use of Evidence: Improving Deception Detection Accuracy of American Law Enforcement Officers' (2016) 31 (4) Journal of Police and Criminal Psychology 1.

35. Larry May, Per Anders Granhag, and Simon Oleszkiewicz, 'Eliciting intelligence using the Scharff-technique: Closing in on the confirmation/disconfirmation tactic' (2014) Journal of Investigative Psychology and Offender Profiling; Oleszkiewicz, Granhag, and S Montecinos, 'The Scharff-Technique: Eliciting Information from Human Sources' (2014) Law and Human Behavior. 
between what the interrogator knows and what the suspect thinks the interrogator knows. Interrogators thus lead the suspect to act in way he likely would not act if he was in full possession of the facts. The Scharff interrogator maintains this asymmetry of knowledge through overstatement of his knowledge and the SUE interrogator, through omission of his relevant knowledge. The suspect or target in a Scharff interrogation is led wrongly to believe that the interrogator already knows everything about his actions, and so it will not compound his predicament to talk to the interrogator. The suspect in a SUE interrogation is invited to narrate his version of the event in question without necessarily knowing that he is a suspect or, if he is, how much inculpating evidence interrogators have against him. His rights are not violated by the interrogator's strategic silence, ${ }^{37}$ but he is deceived all the same in this event in that he makes decisions based on a distorted perception of reality.

Consider for example, the 2010 interrogation of Colonel Russell Williams by Ontario Provincial Police Detective Sergeant Jim Smyth. ${ }^{38}$ Williams, strongly suspected of serial rape and murder, is invited to the police station on the pretense that a traffic stop revealed his truck's tire treads matched the tire prints left at the scene of a recent missing person case. Using a variety of information-gathering and strategic interviewing techniques, including SUE, Smyth does not accuse Williams of any crimes, but instead opens the interrogation by apologetically explaining how the police must interview everyone in the area with the relevant tire treads. The detective explains to Williams his rights and the rationale for every set of questions he poses, all the while implying that the police do not suspect Williams and that they appreciate his cooperation as a concerned citizen to help them go through their investigative procedures. The rapport, the explanations of the procedures, and the polite invitations to provide narrative accounts of his activities clearly seem to give Williams a sense of autonomy in the interrogation room. Yet the non-accusatory gambit interestingly seems to psychologically compel Williams to provide DNA samples and boot impressions when asked, and to refrain, even when the questions become more pointed, to ask for an attorney. The detective did not mention the inculpating evidence he already had against Williams and deceptively presented to Williams an impression that the police view him as a likely innocent, cooperative citizen. As a result, Williams is apparently reluctant to shatter the benign impression he believes police have of him by halting cooperation. So, interestingly, while the accusatory model permits interrogators to tell lies, deceive suspects with their affect, and mislead them with minimization and maximization techniques, the interrogator in an accusatory interrogation may be initially more honest than some non-accusatory interrogators regarding where the suspect stands with the investigation.

C9.P53 Finally, the Perkins interrogator deceives the suspect regarding his true identity, but typically draws on true biographical details in order to make a close connection with the suspect. It is not uncommon for the suspect to literally end up crying on the undercover officer's shoulder. At least in Department 1, the Perkins technique almost always gets results: the chief detective of the Major Crimes division

C9.N38 38. A condensed version of the interrogation in <https://www.youtube.com/watch?v= $9 \mathrm{kcaOH} 3 \mathrm{EwQ}>\mathrm{c}$ accessed 12 January 2019. 
told me that Perkins interrogations had a $98 \%$ success rate in 2016, where success is defined as an admission of guilt with corroborating information, the provision of information creating new investigatory avenues, or the provision of exonerating information. ${ }^{39}$

Apart from the efficacy of non-accusatory approaches - which serves the public's interest - and the relatively benign effects on the suspect, we should also expect these techniques to be less exacting on interrogators. We know that torture can be as psychologically and morally devastating to interrogators as to the victims of torture (more to come). Asking interrogators to lie to, demean, or threaten suspects is also fraught as it asks them to do things that are both ordinarily immoral and easily, subtly exportable into the interrogator's private life. The information-gathering and strategic interviewing approaches ask interrogators to speak sympathetically and respectfully to suspects, inviting them to describe certain events and explain emergent discrepancies. The interrogator is certainly engaging in strategic behavior, selectively concealing information, asking particular questions, and affecting a certain demeanor in order to reach an outcome the guilty suspect would rather not reach. Yet he is doing so in a manner that hardly departs from ordinary polite discourse.

There is no formal data, as far as I know, about the effects on interrogators from information-gathering approaches, SUE, Scharff, and other non-accusatory approaches. Very preliminary, and admittedly anecdotal, information from Perkins interrogators indicates that these interrogations are much more stressful and emotionally draining on interrogators than more traditional, confrontational interrogations. A few interrogators with experience in overt interrogations have also related to me distress over eliciting damaging information from suspects or intelligence targets with whom they have developed, in their words, "trust," "empathy," and/or "rapport" (more to come). If this burden on interrogators is a genuine trend, it is a counterintuitive one. We might expect the burden on suspects and interrogators to decrease as we move along the spectrum from harsh/ineffective methods like torture, through confrontational and deceptive methods like confession-based models, to less harsh/more effective methods relying on rapport building, empathy, and cooperation. Granted, it is debatable where exactly to put Perkins in particular on such a spectrum or even to put it on the spectrum, given that it is a hybrid undercover operation and interrogation and involves a significant deception of the suspect. Yet at least as practiced by Department 1, it also involves rapport-building techniques and the strategic use of evidence and usually results in a deep level of empathy between the suspect and the detective. (While Perkins detectives in Department 1 use the term "rapport" to describe their goal in the interrogation, it is not clear if it is the same type of rapport pursued in other strategic interviews. ${ }^{40}$ ) Overall, consideration of the experience of the suspect in the U.S. Army interrogator (\#1) discussed the emotional difficulty he experienced after eliciting information from ISIS militants with whom he had developed "rapport" (his term), given that the information was later used against them in death penalty cases. Army interrogator \#2 discussed the stress he felt meeting intelligence collection requirements with insurgents with 
actual interrogation suggests to me placement toward the "less harsh" end of the spectrum. Yet again, compared to conventional, confrontational interrogations, the Perkins interrogation is more emotionally draining for interrogators and is causing more ethical concerns for them.

It may be that these preliminary reports about Perkins are the result of a few idiosyncratic responses rather than a genuine problem. Yet in the event these anecdotes are pointing to an emergent problem, we should consider now what we can ask police officers to do in service of the state, and, in the event that Perkins interrogations have significant negative effects on interrogators, whether these interrogations transgress those moral limits. We should consider this question now because many police departments are interested in developing a capacity for Perkins operations and have been sending detectives for training with Department 1 . If it is the intense degree of emotional connection with suspects that causes the interrogators' distress, we should also pay attention to the effect on interrogators for techniques requiring shallower degrees of emotional connection. If what is truly distressing is the betrayal of trust, this dynamic is also present in many types of rapportbased approaches. Interestingly, both a Perkins detective (engaged in covert interrogations) and an Army officer engaging in overt rapport-based interrogations cited the betrayal of trust as deeply troubling. ${ }^{41}$ Even if we set aside concerns regarding officer health and focus on the desire for interrogation efficacy in service of public safety- "compassion fatigue," a well-recognized risk in the medical profession, ${ }^{42}$ will lead practitioners to emotionally withdraw, inhibiting empathy, perhaps inhibiting the affective aspects that help interrogators appear trustworthy, ${ }^{43}$ thereby reducing the effectiveness of various kinds of interrogations focused on relationship building.

\section{ASSESSING INTERROGATION'S EFFECTS ON INTERROGATORS}

State agents do things in service of their state that are superficially at odds with the behavior expected of morally upright people. Service members kill enemy soldiers; police deceive suspects in interrogation; prosecutors ruin people's reputations

whom he had developed "empathy." Interview for project on Counter-Terrorism and Collective Responsibility, sponsored by the European Research Council, Georgetown Law School (18 October 2017).

C9.N41 41. Phone interview with Detective \#3 (14 June 2016); interview with Army interrogator \#1, European Research Council, Georgetown Law School (18 October 2017).

C9.N42 42. See Irina Crumpei and Ion Dafinoiu, 'The Relation of Clinical Empathy to Secondary Traumatic Stress' (2012) 33 Social and Behavioral Sciences 438; Anna Nolte, Charlene Downing, Annie Temane, and Marie Hastings-Tolsma, 'Compassion Fatigue in Nurses: A Metasynthesis' (2017) Journal of Clinical Nursing 1; W Brad Johnson, Michael Bertschinger, Alicia Snell, and Amber Wilson, 'Secondary Trauma and Ethical Obligation for Military Psychologists: Preserving Compassion and Competence in the Crucible of Combat' (2014) 11 (1) Psychological Services 68.

c9.N43 43. See Chapter 5 in this volume by L Brimbal, Col SM Kleinman, S Oleszkiewicz, and CA Meissner for the importance of trust, and particularly affective trust, to rapport building. 
and deprive them of their liberty. Since immoral behavior damages perpetrators' characters and can be expected to cause feelings of shame in mentally normal people, a task for professional ethics is to ensure the actions efficiently contributing to the distinctive ends of professions are morally upright and can be executed by professionals with a clean conscience.

c9.P58 In the field of interrogation, this concern about the professional's own welfare presents another argument against the use of interrogatory torture, one which obtains even in the face of (dubious) consequentialist arguments justifying torture in order to avert a great harm. Torture tends to leave its perpetrators psychologically and morally scarred, unable to form meaningful relationships, depressed, angry, and engaged in numbing and self-destructive behaviors. ${ }^{44}$ Based on the model of professional ethics articulated earlier, state-sponsored torture programs should be prohibited because of the effects on the torturer. ${ }^{45}$

c9.P59 There is sufficient subtlety in the psychological literature to differentiate the type of post-traumatic suffering particularly associated with perpetrators, from that of victims, of trauma. So while both perpetrators and victims are damaged by torture, their suffering takes on different hues. PTSD is characterized by recurrent painful feelings of fear, horror, and helplessness and physiological "fight or flight" arousal responses associated with a traumatic life-threatening event. The victim often seeks to avoid social contact and engage in self-numbing with intoxicants in order to dampen potential triggering experiences. ${ }^{46}$ Whereas PTSD victims are victims or witnesses to trauma (including injuries suffered as a result of nonmoral events, like natural disasters), those suffering from moral injury may have been victims, witnesses, or perpetrators of acts that violated deeply held moral views. Victims of moral injury feel guilt, shame, and anger over the betrayal of trust they experienced or the actions they perpetrated, actions that "create[] dissonance and conflict because it violates assumptions and beliefs about right and wrong and personal goodness." ${ }^{37}$ Those suffering from perpetrator-derived moral injury may feel they are irredeemable and so seek to isolate themselves from others. This isolation is both to avoid condemnation and to avoid further triggers for self-loathing. Whereas victims of PTSD have lost a belief that the world is a basically safe, benign place, the victims of perpetrator-linked moral injury have lost faith in the moral dimensions of the world, and in themselves, as morally upright people.

c9.P60 Thus, we return to the promise of the new alternatives to the confession-based interrogations. Not only would they appear to be much less harmful or distressing to the interrogatee, interrogators who use them would seem to be safer from moral injury since their courteous, respectful, and nonconfrontational behavior is more in line with laypersons' ordinary behavior than older, more confrontational models. Would this not be all the more so with Perkins interrogations, in which interrogators (2004) 10 (3) Science and Engineering Ethics 543. 
engage suspects in a friendly manner, empathizing with and comforting them? Yet again, Perkins interrogators report more emotional distress following their successful interrogations than in traditional interrogation.

A chief detective overseeing all Perkins operations in his department noted to me that he has never seen detectives rejoicing after the successful Perkins operations, even though their targets are serious threats to the community. ${ }^{48}$ (Seventy-five percent of Perkins operations in his department are conducted against homicide suspects, including serial murderers, $10 \%$ for people suspected of serial rape or child molestation, and a few for serial arson and for terrorism. $)^{49}$ Detectives report that this muted reaction is because of the empathy they have developed for the suspects. ${ }^{50}$ They say the level of empathy necessary to build (what they call) "rapport" cannot be faked; undercover officers feel the pain the suspects feel as they talk about their hard lives, regrets, and guilt. Officers invariably have to explore their own memories and expose some of their own feelings in order to authentically engage with suspects over the course of a long day. Since in many cases, detectives come from the same neighborhoods and have the same sort of backgrounds as the suspects (they are selected for "demographic suitability"), there is a feeling in talking to a suspect that the detective's and the suspect's positions might have well been reversed given one or two different events. That final point is relevant to the lingering effect of Perkins interrogations on the interrogators. Therapists might feel empathy with their patients as well, but undercover officers must take advantage of the vulnerability of their interlocutors and the confidence they place in the undercover officers. As one detective put it to me, "You are deceiving someone. He's reaching out to you and leans on you and you gather that information to do him in." 51

By contrast, a detective using a confession-based approach is emotionally shielded from empathizing with the suspect. ${ }^{52}$ The detective maintains all the trappings of authority-suit, badge, sidearm-controlling whether the suspect is handcuffed or not; controlling whether or not the suspect is fed; when he can use the toilet. The detective is in his territory, while the suspect is alone, having first traversed a building full of police in order to reach the interrogation room. The physical design of the interrogation room reinforces the emotional distance between the detective and suspect: they physically confront one another across a table. While the confession-based approach can involve some rapport building, it opens with an accusation of guilt. This immediately places the detective and suspect in a confrontational, rather than cooperative, relationship. Even if adopting a compassionate tone, the detective's performance in the interrogation room does not depart from his actual role. He does not present himself as anything but a state agent confronting a criminal suspect with an accusation of guilt and demanding a

48. Phone interview with Detective \#1 (19 July 2016).

49. Phone interview with Detective \#1 (20 April 2016).

50. Phone interview with Detectives \#1, 2, and 3 (14 June 2016); phone interview with Detectives $\# 1$ and 4 (19 July 2016).

51. Detective \#3 (14 June 2016).

52. Phone interview with Detectives \#1, 2, and 3 (14 June 2016). 
confession. Interrogators using information-gathering and strategic interviewing approaches, particularly in a law enforcement environment, are less confrontational but still enjoy the public markers of authority and the professional distance of a more traditional detective. Detectives tell me they can conduct an accusatory interrogation, even one with some rapport-building elements, and then go home and sleep soundly.

c9.P63 Here, it is worth considering in greater detail what about the Perkins interrogation causes emotional distress to interrogators. Since we do not have broad-based data on the effect of non-accusatory approaches on interrogators, it is important to consider if anecdotally-reported risk factors to interrogators are limited to Perkins interrogations or are present in other types of interrogations as well. What makes Perkins operations disturbing to interrogators is a complicated question since such operations are hybrids of undercover operations and interrogations, and there are several potential variables triggering interrogators' distress. One might speculate that it is the tension of being undercover or the deceiving of suspects rather than the emotional connection that causes officers' distress. Yet the same officers reporting unique stress after a Perkins interrogation do not report this kind of emotional turmoil from ordinary short-term undercover assignments when they pose as drug addicts or people interested in buying illegal weapons. ${ }^{53}$ The same goes for detectives engaging in deceptive stratagems in overt interrogations. ${ }^{54}$ Is it the undercover officer's betrayal of the suspect's trust that is troubling? It makes sense that people would feel guilt after taking advantage of someone's trust to bring about their material harm. Both Perkins and overt, strategic interviewing approaches can put interrogators into a position where they need to gain the suspect's trust and then take advantage of that trust to gather inculpating information. Or is the issue rather the emotional connection interrogators forge with suspects? Emotional distress and compassion fatigue does affect clinicians who form empathic bonds with patients who suffer or pass away without the element of deception or duplicity. ${ }^{55}$ I would speculate that seeing harm come to someone with whom one has developed a connection cannot but be made more distressing when that harm comes about following a perceived betrayal of trust.

c9.P64 Ultimately, I do not think we are yet in the position to consider Perkins as an outlier because of its undercover aspect. I conducted two interviews with Army interrogators who reported similar distress following overt interrogations. As mentioned above, the precise definition of rapport relevant to the interrogative context is still debated by researchers, and it is not clear that interviewed interrogators using the term "rapport" use it the same restricted way that, for example, influential researchers Tickle-Degnen and Rosenthal use it. Again, there is no research with which I am familiar that studies the effects of different interrogation styles on interrogators. Therefore, the concerns raised by Perkins interrogators may or may not be germane to interrogators engaging in other non-accusatory, $\# 1$ and 4 (19 July 2016). 
rapport-based methods. Perhaps even the less intense levels of relational connection in information-gathering or strategic interviewing, with or without a feeling of betrayal, do have short-term or cumulative negative effects on interrogators.

I am not suggesting that we halt training interrogators in non-accusatory methods. Instead, I hope this discussion stimulates empirical researchers to (a) study the effects on interrogators of all types of interrogation; (b) to further clarify the boundaries between the type of rapport useful for interrogations and other types of social or emotional connections; and (c) to consider whether it is the empathy, betrayal, or some other aspect of the Perkins operation that makes it distressing for interrogators.

\section{THE PROPER ATTITUDE FOR INTERROGATORS TOWARD SUSPECTS}

Part III concluded that proper training for interrogators may include training them in the right attitude to have toward the people they interrogate. The non-accusatory interrogation techniques require a balancing of empathetic and analytic approaches to the suspect, treating him sympathetically as a kind of peer but also strategically, as a kind of adversary. Shannon French and Anthony Jack have a compelling recommendation for how people in adversarial professions should view their adversaries in order to reconcile the analytic with empathetic modes of thought the professions require. The challenge these rival modes of thought pose is set forth by French and Jack in a military context but could well apply to interrogations as well:

On the modern battlefield, our troops are asked on the one hand to be ready to fight an enemy with clear-sighted and dispassionate efficiency, and, on the other hand, we expect them to be sensitive to the mores of a foreign culture, enabling them to win the hearts and minds of its citizenry while forming strong and mutually trusting working relationships with members of its military. In other words, we ask them to both highly analytic and highly empathetic. Hence, at first sight, it might appear that the demands of the modern battlefield are simply impossible to manage: they are bound to drive our troops insane. ${ }^{56}$

The particular challenge of non-accusatory interrogations is that interrogators need to deal strategically with a suspect while also developing some kind of trusting connection with him. How can people in adversarial professions manage this duality in a way that is consonant with the model of professional ethics developed earlier in this chapter?

c9.P69 It was once thought necessary in the military to encourage service personnel to dehumanize their enemy in order to overcome their natural aversion to killing, but there is significant evidence now to connect dehumanization with psychological trauma for the dehumanizer. ${ }^{57}$ Just the same, French and Jack argue that it is 
also unrealistic to demand that service personnel have the same empathetic view of their enemies that is appropriate for strangers to have of one another in civilian life, wherein strangers ideally should see each other as equally human, with equally important interests, emotional lives, aspirations, friendships, and familial relations. This sort of empathetic view would seem incompatible with the task of taking lives, or at least to place a painful emotional burden on those service personnel who could perhaps still act in deference to their professional obligations. The same consideration would seem to apply to detectives who need to collect the evidence that will put guilty suspects in jail.

French and Jack advance an intriguing proposal for how service personnel should view their enemies - even within the scope of adhering to military normsin order to both efficiently execute their tasks on the battlefield and then reconcile themselves to what they have done after the war. They look to surgeons for a model of professionals who are able, at best, to toggle between empathetic and analytic modes of thinking, seeing their patients as individuals when they are explaining their prognoses, and then seeing them as "biological machines" when they are operating. Both models are important. The unemotional, purely analytic doctor who sees patients simply as a disease vector would come across as cruelly indifferent. Yet even the patient offended by her surgeon's bedside manner would not want her surgeon to be emotional when it came time to operate.

French and Jack are alive to the risks associated with objectifying enemies as mere "targets" in wartime, but see it as a "lesser evil" enabling service personnel to function on the battlefield without departing irrevocably from a peacetime moral outlook seeing all humans as equally valuable. ${ }^{58}$ Service personnel should perhaps be encouraged to temporarily objectify their enemies but then to return to an acknowledgment after the battle or war that their enemies are people with equal worth to themselves.

This is an intriguing and plausible proposal for professionals that might well meet the desiderata articulated in Section III: professionals must be able to successfully execute their socially-valuable professional tasks without compromising their humanity. We can imagine detectives dispassionately pursuing a suspect, gathering evidence they know will place the person in jail, looking at him more as a problem to be solved than a person, while also, at the end of the day, recognizing that he is a person. It might be morally wholesome for the detective to later reflect that the suspect is a person who did a bad thing-maybe not so different than the detectivewho might well have turned out differently if given different opportunities in life. This approach might be fruitful in many law enforcement contexts. Yet objectifying the suspect might be in tension with developing empathy for a suspect and a failure to empathize may inhibit the type of connection conducive to a suspect's cooperation. Readers can reflect how alienating it feels to share something significant with someone who (one realizes) is only feigning empathy or sympathy. 


\section{A PRESCRIPTION FOR INTERROGATORS}

Assuming that novel styles of interrogation are respectful of suspects' rights, highly efficacious, and likely to be adopted by more police departments, what can my professional ethics model suggest for the care of interrogators? I can here only sketch out some suggestions. The non-accusatory approaches described in this chapter are novel and their effects on interrogators are not well understood. Prescriptions for emotional health also, of course, exceed an ethicist's competence.

If interrogations can be consistent with the moral framework articulated in Section III of this chapter, wherein professional morality is understood as an institutionally mediated expression of nonprofessional morality, interrogators have to be trained to be able to conduct interrogations without suffering serious moral or psychological distress. It is not good enough for the state to simply consider interrogators disposable. I cannot articulate the precise mix of mental scripts an emotionally healthy interrogator will internalize, but the correct path likely includes both cognitive and affective elements. Philosophy can offer justifications to furnish the cognitive element, and psychology may be able to offer therapeutic practices to assist officers.

As French and Jack argue, justifying one's actions to oneself and others is important to maintain one's sense of moral integrity-and to enjoy the psychological wellbeing that goes along with it. The most problematic aspect of some interrogations is the betrayal of the suspect's trust. The officer needs to remember that the person ceded the legitimate expectation that some of his rights would be respected when he committed a serious crime. Further, the criminal secrets he reveals to the trusted interrogator are not morally privileged secrets he is entitled to keep. They are not, for example, like secrets about his religious views or familial affections. The fact that he has not voluntarily confessed his crime compounds his crime by denying victims' or victims' families closure, justice, and restitution. His silence also of course, permits his continued liberty, and perhaps, continued criminal behavior.

The interrogator's successful elicitation of incriminating information may well mean the suspect's conviction and incarceration. Yet the guilty party has no right to avoid punishment. There is no need to occupy a moralistic high ground here. Many criminals are people who grew up in violent and impoverished circumstances without any real chance at avoiding a criminal lifestyle. Ours is a society characterized by savage inequalities. Some detectives intimated to me that they felt guilty over playing a role in a structurally unjust system. ${ }^{59}$ Detectives who are rightly troubled by the injustice of our society should consider that criminals who are sympathetic for this reason would still be ill-served by avoiding punishment. While their suffering may seem slight compared to the suffering of their victims, perpetrators are morally harmed by performing unjust acts. The officer halts the suspect from incurring further moral degradation. Under some circumstances, a forced end to criminal activity (even involving incarceration) may create the conditions for the convicted person's eventual redemption.

Further, no matter what the suspect's background, he cannot be allowed to continue to commit violent crimes. The Perkins interrogator, in particular, might 
consider that in contrast to a less refined interrogator, he or she at least gave the suspect a sympathetic hearing and maybe brought him a little bit of comfort on his way to his necessary incarceration. One middle-aged female detective told me that she inevitably played a maternal role with younger female suspects in Perkins interrogations; the intimate, non-criminal secrets suspects shared with her gave her pause about the rightness of her role. "It always ends in tears," she said. ${ }^{60}$ Here, let me suggest, that in stressful times, we have probably all shared some painful experience with a stranger or someone we just barely know. Even though the detective was playing a professional role, she did offer a genuinely sympathetic ear, and the suspect did find some solace in sharing what she had bottled up inside.

There is a curious similarity in the stresses afflicting some interrogators and clinicians in that both have to regularly express empathy and nonjudgmental understanding with strangers in emotional extremis. It is possible to experience a physiological stress reaction when listening to someone relate a traumatic event, even to the point, over time, of experiencing PTSD. ${ }^{61}$ This risk should probably be discussed in interrogator training, alongside lessons about how to minimize it. Suggestions taken from the medical literature may be of some help to interrogators in combating compassion fatigue or related emotional stress. A common theme seems to be the need to turn experiences from lived, subjective phenomena into artifacts through conversation and analysis. The goal is to turn an experience that is mixed in with the flow of a person's memories, emotions, hopes, and plans-all that makes him, him-into an impersonal, detachable event, like something he reads about in the newspaper. To this end, interrogators should debrief with peers and sympathetic supervisors after each session. ${ }^{62}$ Debriefing may normalize certain feelings, point out problem behaviors, and provide an opportunity to receive encouragement. This process may also help turn the experience with the suspect into something apart from the interrogator, something distinct from his own nonprofessional persona.

69.P79 It seems important to develop exercises with some interrogators to limit the effect of their emotional attachment with suspects. One interesting suggestion to this end, from a veterinary journal, is for the practitioner to go through self-assigned rituals at the end of the working day (perhaps removing certain clothes or jewelry only worn on assignment or filing paperwork summarizing the day's activities) designed to physically demarcate the boundary between work and personal life and underline the notion, in the law enforcement context, that the suspect's pain is not for the officer to bring home. ${ }^{63}$ Further sensible advice for any stressful occupation (19 October 2016).

62. Stephen Mand and Donald Sheehan, 'Managing Undercover Stress: The Supervisor's Role' (1999) 68 (2) FBI Law Enforcement Bulletin 1, 3, 5; Vincent McNally, 'The FBI's Critical Incident Stress Management Program’ FBI Law Enforcement Bulletin. 
includes taking significant downtime between difficult operations and regimenting time for exercise, spiritual practice, and hobbies in order to decompress. ${ }^{64}$

There is less consensus to be found in the psychological literature beyond these sensible suggestions. Some scholars who have studied compassion fatigue in clinicians suggest that doctors and nurses cultivate and project empathy, but not compassion, with patients. Empathy is here defined as a cognitive understanding of what the patient is subjectively experiencing and compassion, as co-feeling with the patient. ${ }^{65}$ The patient talking to an empathetic clinician feels that he is understood and that his feelings are validated, but, I take it, the clinician views the patient as a kind of intellectual specimen, perhaps objectifying him or her in the way advocated by French and Jack. Another study suggests only "dipping" into empathy and balancing emotional aspects of the term with cognitive elements. ${ }^{66}$ Yet other researchers counsel that psychologists become ineffective when they are no longer able to process a client's experiences on an emotional level, restricting themselves to cognitive processing alone. ${ }^{67}$ Again, this would seem to be directly relevant to those interrogators who need to appear genuinely emotionally engaged with the suspect in order to be effective.

\section{CONCLUSION}

In this chapter, I develop a theory of professional ethics that can be used to address the limits of what laypeople can demand of professionals. The model indicates that state agents like police cannot be asked to sacrifice their physical, mental, or moral health for the sake of citizens. Research done since the mid-1980s has produced interrogation techniques that are more effective, reliable, and humane for suspects, crime victims, and witnesses than confession-based approaches. Given some anecdotal reports of distress among interrogators using some of these techniques, I suggested that we should pay attention to the effects of non-accusatory interrogations on interrogators as these approaches become more widely adopted. Specifically, I suggest we need (a) to study the effects on interrogators of all types of interrogation; (b) to further clarify the boundaries between the type of rapport useful for interrogations and other types of social or emotional connections; and (c) to consider whether it is the empathy, betrayal, or some other aspect of the Perkins operation that makes it distressing for interrogators.

64. W Brad Johnson, Michael Bertschinger, Alicia Snell, and Amber Wilson, 'Secondary Trauma and Ethical Obligation for Military Psychologists: Preserving Compassion and Competence in the Crucible of Combat' (2014) 11 (1) Psychological Services 68, 71; Anna Nolte, Charlene Downing, Annie Temane, and Marie Hastings-Tolsma, 'Compassion Fatigue in Nurses: A Metasynthesis' (2017) Journal of Clinical Nursing 1, 10. and Ethical Obligation for Military Psychologists: Preserving Compassion and Competence in the Crucible of Combat' (2014) 11 (1) Psychological Services 68, 69. 